\title{
(S)-Ketamine in Refractory and Super-Refractory Status Epilepticus: A Retrospective Study
}

\author{
Julia Höfler ${ }^{1,2}$ - Alexandra Rohracher ${ }^{1,2}$ - Gudrun Kalss ${ }^{1,2}$ • Georg Zimmermann ${ }^{1,2,3}$. \\ Judith Dobesberger $^{1,2} \cdot$ Georg Pilz $^{1,2}$ - Markus Leitinger1,2 Giorgi Kuchukhidze $^{1,2,4}$. \\ Kevin Butz ${ }^{1,2,5} \cdot$ Alexandra Taylor $^{1,2,5} \cdot$ Helmut Novak ${ }^{1,2} \cdot$ Eugen Trinka $^{1,2}$ (1)
}

Published online: 27 July 2016

(C) The Author(s) 2016. This article is published with open access at Springerlink.com

\begin{abstract}
Objective The aim was to describe the safety and efficacy of $(S)$-ketamine $[(S)$-KET] in a series of patients with refractory and super-refractory status epilepticus (RSE and SRSE) in a specialized neurological intensive care unit (NICU).

Methods We retrospectively analyzed the data of patients with RSE and SRSE treated with (S)-KET in the NICU, Salzburg, Austria, from 2011 to 2015. Data collection included demographic features, clinical presentation, diagnosis, electroencephalogram (EEG) data, anticonvulsant treatment, timing, and duration of treatment with $(S)$ KET. Outcomes were seizure control and death.

Results A total of 42 patients (14 women) with RSE and SRSE were treated with $(S)$-KET. The median duration of status epilepticus (SE) was 10 days [first quartile (Q1) 5.0,
\end{abstract}

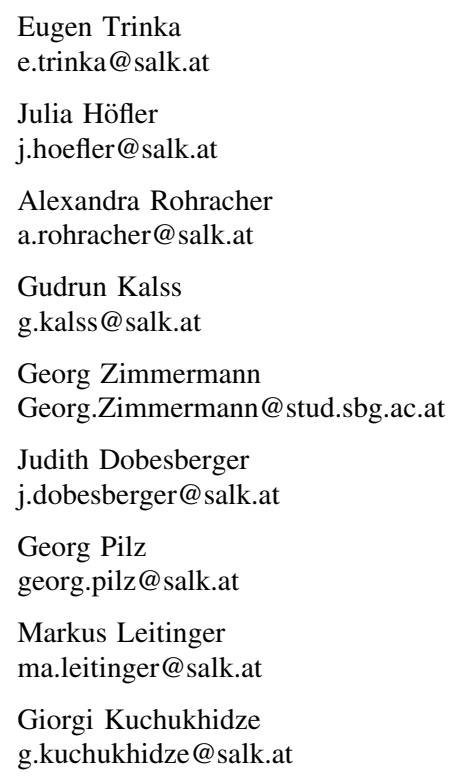

Q3 21.0]; the median latency from SE onset to the first administration of $(S)$-KET was 3 days (Q1 2.0, Q3 6.8). Prior to $(S)$-KET administration, patients had received a median of two (Q1 2.0, Q3 3.0) anesthetics and three (Q1 2.0, Q3 4.0) antiepileptic drugs. Forty percent of patients (17/42) received propofol: $65 \%$ prior to $(S)$-KET; $35 \%$ at the same time with $(S)$-KET. Seven patients received a median bolus of (S)-KET of $200 \mathrm{mg}$ (Q1 200, Q3 250) followed by a continuous infusion, while 35 started with a continuous infusion (maximum rate median $2.55 \mathrm{mg} / \mathrm{kg} / \mathrm{h}$; Q1 2.09, Q3 3.22). In $64 \%$ of patients (27/42), (S)-KET was the last drug before SE cessation; in five patients, it was given with propofol at the same time. Median duration of administration was 4 days (Q1 2.0, Q3 6.8). Overall (S)KET treatment was well tolerated, adverse effects were not observed, and overall mortality was $45.2 \%$.

Kevin Butz

k.butz@salk.at

Alexandra Taylor

a.taylor@salk.at

Helmut Novak

h.novak@salk.at

1 Department of Neurology, Christian Doppler Klinik, Paracelsus Medical University of Salzburg, Ignaz-Harrer-Str. 79, 5020 Salzburg, Austria

2 Centre for Cognitive Neuroscience, Salzburg, Austria

3 Department of Mathematics, Paris Lodron University, Salzburg, Austria

4 Department of Neurology, Medical University of Innsbruck, Innsbruck, Austria

5 Department of Psychology, Paris Lodron University, Salzburg, Austria 
Conclusions Treatment of SRSE in adult patients with $(S)$ KET led to resolution of status in $64 \%$. No adverse events were found, indicating a favorable safety profile.

\section{Key Points}

$(S)$-Ketamine $[(S)$-KET] can be used safely in patients with refractory and super-refractory status epilepticus (SE), with a good response rate of $64 \%$.

Earlier treatment of SE with $(S)$-KET or the racemic mixture should be considered.

\section{Introduction}

Refractory status epilepticus (RSE) is defined by failure of two antiepileptic medications and the need for anesthetic treatment. Super-refractory status epilepticus (SRSE) is specified by ongoing or recurring clinical or electroencephalographic seizure activity $24 \mathrm{~h}$ or more after initiation of anesthetic treatment [1]. Between 23 and $42 \%$ of all patients with status epilepticus (SE) are refractory or superrefractory $[2,3]$, and the mortality rate can increase up to $40 \%$ [4]. Drug resistance in SE is caused by many factors involving molecular and functional maladaptive changes. Modifications in the functional properties of gamma aminobutyric acid $\mathrm{A}\left(\mathrm{GABA}_{\mathrm{A}}\right)$ receptors, as well as an enhanced trafficking of $\mathrm{GABA}_{\mathrm{A}}$ receptors beyond increased expression of glutamate receptors $\alpha$-amino-3hydroxy-5-methyl-4-isoxazolepropionic acid (AMPA) receptor and $N$-methyl-D-aspartate (NMDA) receptor subtypes, which shift to the synaptic membrane, are key elements in the development of drug-resistant SE [5].

GABA-ergic drugs, such as benzodiazepines and phenobarbital, have a good efficacy in the early stages of SE, but their effectiveness decreases rapidly during the later stages in humans. Therefore, drugs with other mechanisms are recommended for the established and refractory stages of SE [6-8].

Ketamine (KET) has a strong antagonistic effect on the NMDA-glutamate receptor. Its half-life is $2-3 \mathrm{~h}$, and KET undergoes an extensive hepatic metabolism [9]. Animal models (hippocampal electrical stimulation or pilocarpine animal models) have demonstrated the efficacy of KET in RSE in rats, even in late stages, when GABA-ergic drugs have failed $[9,10]$. The most significant adverse effects of KET are hallucinations and sympathetic adrenergic effects.

KET is a racemic mixture containing equal amounts of two enantiomers: $(S)$ - and $(R)$-KET. KET is extensively metabolized by $N$-demethylation, producing norketamine, a non-competitive NMDA receptor antagonist that may also exhibit enantioselective pharmacological activity. (S)KET has different pharmacodynamic activities and is a two- to threefold more potent analgesic agent than $(R)$ KET [11]. ( $S$ )-KET administered alone has a higher clearance than in the racemic mixture, resulting in quicker elimination, shorter duration of action, and a faster recovery from anesthesia. The $S$ enantiomer was also associated with a more rapid recovery of psychomotor skills than the racemic mixture $[12,13]$. Thus the use of $(S)$-KET in RSE should have clinically relevant advantages.

The aim of this study was to explore the feasibility, efficacy, safety profile, and effect on outcome of intravenous $(S)$-KET in patients with RSE and SRSE.

\section{Methods}

\subsection{Patients}

We retrospectively identified all patients with SE who were treated at the neurological intensive care unit (NICU) of the Department of Neurology, Paracelsus Medical University of Salzburg between 2011 and $2015(n=344)$, utilizing the electronic hospital database. Forty-two out of 344 patients received treatment with $(S)$-KET. We analyzed demographic data, duration, etiology and type of SE, cotherapeutic agents [antiepileptic drugs (AEDs) as well as other anesthetics], response to $(S)$-KET, and adverse effects during treatment as well as outcome after SE by retrospective chart review. Diagnosis of SE was made clinically in the case of prominent motor symptoms or by electroclinical criteria for nonconvulsive status epilepticus (NCSE) [14, 15]. The clinical definition of SE was based on the proposal of the International League Against Epilepsy (ILAE) Task Force along two taxonomic criteria: presence of motor symptoms and impairment of consciousness. Hence, we distinguished between (a) SE with prominent motor symptoms (including tonic clonic SE, myoclonic SE, focal motoric SE, tonic SE and hyperkinetic SE) and (b) SE without prominent motor symptoms (NCSE) with or without coma. Etiology was grouped into cryptogenic (unknown cause) and symptomatic (known cause), which were further divided into acute, remote, and progressive symptomatic [16].

RSE is defined by failure of benzodiazepines, intravenous antiepileptic medications, and the need for anesthetic treatment. SRSE is defined by ongoing or recurring clinical or electroencephalographic seizure activity for $24 \mathrm{~h}$ or more after beginning anesthetic therapy [1]. The duration of SE from seizure onset to last documented seizure activity evaluated either clinically (in case of SE with 
prominent motor features) or with electroencephalogram (EEG) data (in case of NCSE) was grouped into (a) less than $30 \mathrm{~min}$, (b) 30-60 min, (c) 1-24 h, (d) 1-7 days, and (e) more than 7 days. If seizure onset was not observed, the duration of SE was estimated based on the available prehospital information.

\subsection{Treatment and Outcome}

In our hospital, drug management of convulsive SE and NCSE in adults is performed according to our previously published treatment protocols [7, 8, 17-19]. For convulsive SE and comatose NCSE, we follow the treatment protocol as indicated in Trinka et al. [8] in 2015 and Trinka et al. [19] in 2016. For non-comatose NCSE, we follow a less aggressive approach with benzodiazepines followed by valproic acid or levetiracetam as needed [18]. Cessation of SE was defined as disappearance of ictal symptoms without any subtle signs of ongoing subclinical seizure activity, or electroencephalographic seizure activity within $72 \mathrm{~h}$. For initiation of $(S)$-KET treatment, a prolonged standard EEG recording was carried out followed by intermittent EEG recording as needed. The decision to use $S$-KET was based on the treatment protocol and the best practice of the physician in charge. The last AED administered before SE cessation was defined as the termination drug, regardless of the latency between its first administration and SE cessation. To estimate mortality risk, the epidemiology-based mortality score in SE (EMSE) (cutoff level for bad outcome 64 points) [20] was used. Outcome after SE was assessed by the Modified Rankin Scale (mRS).

This retrospective, non-invasive study was approved by the institutional review board.

\subsection{Statistics}

Continuous variables were summarized using median, minimum, and maximum; categorical variables were summarized using counts and percentages. As our sample size is small, which may influence the validity of the logistic regression model, we did not use this model [21]. Instead, we decided to make inference only for some particular variables, which were chosen beforehand. For binary variables, we used Egon Pearson's version of the Chisquared test [22], and for continuous variables, we used a nonparametric test referred to as the Brunner-Munzel test [23]. Due to the skewness of the respective distributions and small sample sizes (non-responders $n=15$, deceased $n=19$ ), this test is more appropriate than the $t$ test or the Wilcoxon test. To adjust the $p$ values for multiple comparisons, we applied the Bonferroni-Holm method [24].

For the calculation of odds ratio estimates and the corresponding $95 \%$ confidence intervals (CIs), we used the maximum likelihood estimates and the Woolf logit intervals, respectively [25].

The analysis of the data was carried out using $\mathrm{R}^{\circledR}$ [26].

\section{Results}

\subsection{Patients and Demographics}

We identified 42 of 344 patients (12\%) with SE who were treated with $(S)$-KET; three of them had an RSE and 39 an SRSE (Table 1). Median age at time of SE was 67 years [first quartile (Q1) 59.3, Q3 72.0]. Forty-eight percent were women. Most of them $(83 \%, 35 / 42)$ had an acute symptomatic etiology and $17 \%(7 / 42)$ a remote symptomatic etiology. Specific etiologies were postanoxic encephalopathy in $33 \%$ (14/42), cerebrovascular in $17 \%$ (7/42), central nervous system (CNS) infection in $10 \%$ (4/ 42), and CNS tumor in $7 \%(3 / 42)$. Seven patients $(17 \%)$ had a previous history of seizures. Etiology was unknown in $17 \%(7 / 42)$ of patients. Comatose NCSE was present in $67 \%(28 / 42)$, myoclonic SE in $14 \%(6 / 42)$, tonic clonic $\mathrm{SE}$ in $14 \%(6 / 42)$, and focal motor SE in $5 \%(2 / 42)$ of patients. Median duration of SE was 10 days (Q1 5.0, Q3 21.0); median latency from SE to $(S)$-KET 3 days (Q1 2.0, Q3 6.8); median number of previously failed AEDs was three (Q1 2.0, Q3 4.0); and median number of unsuccessful used anesthetic drugs was two (Q1 2.0, Q3 3.0).

\section{2 (S)-KET Administration}

$(S)$-KET treatment was introduced after a median of 3 days (Q1 2.0, Q3 6.8) of SE. In the majority of patients (83\%), treatment was started via continuous infusion with a median rate of $2.39 \mathrm{mg} / \mathrm{kg} / \mathrm{h}(S)$-KET (Q1 1.52, Q3 3.02). Only seven patients received a bolus dose of median $200 \mathrm{mg}$ (Q1 200, Q3 250) followed by continuous infusion. Median duration of $(S)$-KET administration was 4 days (Q1 2.0, Q3 6.8).

\subsection{1 (S)-KET and Propofol}

Seventeen patients $(40 \%)$ received propofol, $65 \%(11 / 17)$ of them prior to $(S)$-KET (at least $12 \mathrm{~h}$ and with a maximum of $72 \mathrm{~h}$ before) and $35 \%(6 / 17)$ at the same time with $(S)$-KET. Propofol dose ranged from 2 to $6 \mathrm{mg} / \mathrm{kg} / \mathrm{h}$.

\subsection{Efficacy}

Finally, in $64 \%(27 / 42)$ of patients $(S)$-KET was the last drug administered before SE cessation; $15 \%$ (4/27) of them received $(S)$-KET and propofol at the same time. In the group with propofol as the initial agent, 11 patients got 
Table 1 Demographic and clinical data with respect to $(S)$-KET response

\begin{tabular}{|c|c|c|c|}
\hline & $\begin{array}{l}\text { Responders } \\
(n=27)\end{array}$ & $\begin{array}{l}\text { Non-responders } \\
(n=15)\end{array}$ & Total $(n=42)$ \\
\hline Age (years): median (1st and 3rd quartiles) & $68(61.5,74.0)$ & $62(54.5,71.0)$ & $67(59.3,72.0)$ \\
\hline Gender: F/M & $14 / 13$ & $6 / 9$ & $20 / 22$ \\
\hline Hypoxia: yes/no & $9 / 18$ & $5 / 10$ & $14 / 28$ \\
\hline Acute/remote symptomatic & $22 / 5$ & $13 / 2$ & $35 / 7$ \\
\hline Prior history of epilepsy: yes/no & $5 / 22$ & $2 / 13$ & $7 / 35$ \\
\hline SE duration (days): median (1st and 3rd quartiles) & $7(4.0,14.0)$ & $20(12.0,29.5)$ & $10(5.0,21.0)$ \\
\hline SE classification: convulsive/nonconvulsive/focal/myoclonic & $6 / 16 / 1 / 4$ & $0 / 12 / 1 / 2$ & $6 / 28 / 2 / 6$ \\
\hline ICU duration (days): median (1st and 3rd quartiles) & $16(12.5,21.5)$ & $22(10.0,44.5)$ & $16(11.0,30.5)$ \\
\hline Loading dose administered: yes/no & $3 / 24$ & $4 / 11$ & $7 / 35$ \\
\hline Maximum infusion rate (mg/kg/h): median (1st and 3rd quartiles) & $2.77(2.09,3.23)$ & $2.50(2.01,3.17)$ & $2.55(2.09,3.22)$ \\
\hline Maximum infusion rate $\geq 2 \mathrm{mg} / \mathrm{kg} / \mathrm{h}$ : yes $/ \mathrm{no}$ & $22 / 5$ & $12 / 3$ & $34 / 8$ \\
\hline Median infusion rate (mg/kg/h): median (1st and 3rd quartiles) & $2.30(1.57,3.14)$ & $2.41(1.28,2.71)$ & $2.39(1.52,3.02)$ \\
\hline Median infusion rate $\geq 2 \mathrm{mg} / \mathrm{kg} / \mathrm{h}$ : yes $/$ no & $17 / 10$ & $9 / 6$ & $26 / 16$ \\
\hline Number of previously failed AEDs: median (1st and 3rd quartiles) & $3(2.0,3.5)$ & $3(2.0,4.0)$ & $3(2.0,4.0)$ \\
\hline Number of unsuccessful used anesthetic drugs: median (1st and 3rd quartiles) & $2(2.0,2.5)$ & $2(2.0,3.0)$ & $2(2.0,3.0)$ \\
\hline$(S)$-KET with propofol: yes/no & $9 / 18$ & $8 / 7$ & $17 / 25$ \\
\hline Latency from SE to $(S)$-KET (days): median (1st and 3rd quartiles) & $3(2.0,6.0)$ & $4(2.0,6.5)$ & $3(2.0,6.8)$ \\
\hline Duration of (S)-KET administration (days): median (1st and 3rd quartiles) & $4(2.0,7.5)$ & $4(3.5,6.0)$ & $4(2.0,6.8)$ \\
\hline EMSE: positives, $n(\%)$ & $23(85.2)$ & $11(73.3)$ & \\
\hline Deceased: $n(\mathrm{TP}+\mathrm{FN})$ & $17(16+1)$ & $8(7+1)$ & \\
\hline Study group specific PPV, \% & 69.6 & 63.6 & \\
\hline Study group specific NPV, \% & 75.0 & 75.0 & \\
\hline
\end{tabular}

$A E D$ antiepileptic drug, $E M S E$ epidemiology-based mortality score in status epilepticus, $F$ female, $F N$ false negative, $I C U$ intensive care unit, $M$ male, $N P V$ negative predictive value, $P P V$ postive predictive value, $S E$ status epilepticus, $(S)$-KET (S)-ketamine, $T P$ true positive

seizure free. In the group with propofol and $(S)$-KET administration at the same time, SE was stopped in four out of six patients. None of the following variables were related to the termination rate: age, hypoxia, duration of $(S)$-KET administration, combination with propofol, infusion rate of more than $2 \mathrm{mg} / \mathrm{kg} / \mathrm{h}(S)$-KET, the use of a loading dose, and number of previously failed drugs (Table 2).

\subsection{Safety}

Overall $(S)$-KET treatment was well tolerated; no adverse effects were observed.

\subsection{Outcome}

The overall mortality rate within 4 weeks of occurrence of SE was $45.2 \%$ of patients (Table 3), most of whom died due to cardio-respiratory failure. Three months after the occurrence of SE, the mortality rate increased to $55 \%$ (at this time, $85 \%$ of all patients could be followed up), and 12 months afterwards, the mortality rate increased to
$60 \%$ (79\% of all patients could be followed up). Only seven patients had a survival time of more than 3 years with an outcome according to mRS; two of seven patients had no significant disability, three severe disabilities, and two moderate disabilities. Older patients had a higher mortality $[p=0.0014$, relative effect $0.8 \quad(95 \%$ CI 0.66-0.94)] (Table 4). No significant differences regarding duration of SE, median infusion rate, use of a loading dose, number of previously failed AEDs, and duration of $(S)$-KET administration could be identified in our cohort (Tables 3, 4).

\subsubsection{Outcome in Postanoxic Patients}

We analyzed posthypoxic patients separately. The termination rate was $64 \%$ (95\% CI 38.8-83.7). The mortality rate 4 weeks after occurrence of SE was $36 \%$ (95\% CI 16.3-61.2). Eight out of 14 patients were treated with hypothermia. Compared to the patients with other etiologies, we could not find any significant differences regarding median infusion rate, loading dose, and duration of $(S)$ KET administration. 
Table 2 Associations with the number of responders to $(S)$-KET treatment

\begin{tabular}{|c|c|c|c|}
\hline Variable & Test & $p$ value (adjusted) ${ }^{\mathrm{a}}$ & Effect measure: estimate $(95 \% \mathrm{CI})$ \\
\hline Hypoxia: yes/no & E. Pearson's Chi-squared test & 1.00 & Odds ratio $^{\text {b }}: 1.00(0.26-3.81)$ \\
\hline Propofol: yes/no & E. Pearson's Chi-squared test & 1.00 & Odds ratio: $0.44(0.12-1.59)$ \\
\hline Median infusion rate $\geq 2 \mathrm{mg} / \mathrm{kg} / \mathrm{h}$ : yes $/ \mathrm{no}$ & E. Pearson's Chi-squared test & 1.00 & Odds ratio: $1.13(0.31-4.14)$ \\
\hline Loading dose administered: yes/no & E. Pearson's Chi-squared test & 1.00 & Odds ratio: $0.34(0.07-1.80)$ \\
\hline Number of previously failed AEDs & Brunner-Munzel test & 1.00 & Relative effect ${ }^{\mathrm{c}}: 0.45(0.25-0.66)$ \\
\hline Duration of $(S)$-KET administration & Brunner-Munzel test & 1.00 & Relative effect: $0.46(0.28-0.64)$ \\
\hline Latency from SE to $(S)$-KET & Brunner-Munzel test & 1.00 & Relative effect: $0.44(0.26-0.62)$ \\
\hline Age & Brunner-Munzel test & 1.00 & Relative effect: $0.62(0.42-0.82)$ \\
\hline
\end{tabular}

$A E D$ antiepileptic drug, $C I$ confidence interval, $S E$ status epilepticus, $(S)$-KET (S)-ketamine

${ }^{\text {a }}$ The reported $p$ values have been adjusted for multiple comparisons using the Bonferroni-Holm correction

b The reported odds ratio represents the quotient of the odds for responding given hypoxia = yes and the odds for responding given hypoxia $=$ no. Analogous interpretations hold for the other odds ratios reported in the table

c This quantity can be interpreted as an estimate of the probability that the value of the variable is lower for non-responders than for responders

\section{Discussion}

This study explored the efficacy and safety of $(S)$-KET treatment for patients with RSE or SRSE in the NICU of a single center. Among all patients with intravenous $(S)$ KET, $64 \%$ received $(S)$-KET as the last drug and $15 \%$ of them received $(S)$-KET and propofol at the same time. No specific adverse effects were related to the administration of intravenous (S)-KET, indicating a favorable safety profile. Other important co-variables, such as certain etiologies or age [27], were independent from termination rate-as well as duration and dose of $(S)$-KET, combinatorial treatment with propofol, the use of a loading dose, and the number of previously failed drugs. Patients with posthypoxic encephalopathy did not differ in termination rate compared to other etiologies. The majority of them were treated with hypothermia. In our study, the mortality rate was lower than in other studies [28-30]. This might be explained by differences in the source population. Patients with more severe hypoxic encephalopathies are treated at a different institution.

A previous multicenter study suggested a lower response rate when infusion rates were lower than $0.9 \mathrm{mg} /$ $\mathrm{kg} / \mathrm{h}$ and when KET followed the failure of seven or more drugs [31], which was not confirmed by our series. The use of $(S)$-KET with a higher potency compared with the racemate could be an explanation, but there is no support for this hypothesis from preclinical studies or other case series in humans.

Previous literature on the use of KET in SE for adults is limited to four retrospective case series and a few single case reports [31-45]. The termination rate in our case series with $(S)$-KET is largely in line with the results of case series using the racemic mixture [31,33]. Only one recently published case series reported an outstanding resolution rate of $91 \%$ [32]. The authors of this study explained their high success rate with the early administration of KET and/or propofol (within 24-48 h). However, detailed numbers regarding how many patients received KET within this time were not reported.

One explanation why the higher potency of the $S$ enantiomer of KET was not translated into a higher efficacy compared with the racemic mixture might be the low median dose of continuous infusion used in our study. Our doses of the continuous infusions were quite similar to the doses of other studies with the racemic mixture of KET $[31,33]$, whereas our median maximum dose (median 2.55, Q1 2.09, Q3 3.22) was low compared with the studies with intravenous KET where maximum rates of $10.5 \mathrm{mg} / \mathrm{kg} / \mathrm{h}$ were applied [32].

Another reason for our relatively low termination rate despite the use of $(S)$-KET could be the method of drug administration; in comparison to other case series with similar termination rates, a relatively low number of our patients $(17 \%)$ received $(S)$-KET as a bolus dose, which may have resulted in a lower peak brain concentration $[31,35]$.

In our study, overall mortality was $45.2 \%$, which was found to be positively correlated with increasing age, but not with response to $(S)$-KET. This finding is also supported by the substantial rate of patients with a high EMSE score, indicating an elevated risk of mortality.

\subsection{Strengths and Limitations}

Two limitations of this study are its retrospective study design and single center source. Therefore, there is a risk of incomplete data on seizure onset, duration of SE before treatment, as well as exact clinical manifestation at onset. Furthermore, due to the retrospective design, only the 
Table 3 Demographic and clinical data with respect to mortality

\begin{tabular}{lll}
\hline & Survivor ${ }^{\mathrm{a}}(n=23)$ & Nonsurvivor $(n=19)$ \\
\hline Age (years): median (1st and 3rd quartiles) in years & $60(54.0,69.5)$ & $72(64.0,78.5)$ \\
Gender: F/M & $8 / 15$ & $12 / 7$ \\
Responder: yes/no & $13 / 10$ & $14 / 5$ \\
Hypoxia: yes/no & $9 / 14$ & $5 / 14$ \\
Acute/remote & $19 / 4$ & $16 / 3$ \\
Prior history of epilepsy: yes/no & $4 / 19$ & $3 / 16$ \\
SE duration (days): median (1st and 3rd quartiles) & $14(7.5,25.0)$ & $9(4.5,15.5)$ \\
SE classification: convulsive/nonconvulsive/focal/myoclonic & $4 / 13 / 2 / 4$ & $2 / 15 / 0 / 2$ \\
NICU duration (days): median (1st and 3rd quartiles) & $20(11.0,37.5)$ & $15(10.5,22.0)$ \\
Loading dose administered: yes/no & $6 / 17$ & $1 / 18$ \\
Maximum infusion rate (mg/kg/h): median (1st and 3rd quartiles) & $2.50(2.10,3.22)$ & $2.85(1.90,3.22)$ \\
Maximum infusion rate $\geq 2$ mg/kg/h: yes/no & $20 / 3$ & $14 / 5$ \\
Median infusion rate (mg/kg/h): median (1st and 3rd quartiles) & $2.41(1.60,3.15)$ & $2.38(1.34,2.7)$ \\
Median infusion rate $\geq 2$ mg/kg/h: yes/no & $15 / 8$ & $11 / 8$ \\
Number of previously failed AEDs: median (1st and 3rd quartiles) & $3(2.0,4.0)$ & $3(2.0,3.5)$ \\
Number of unsuccessful used anesthetic drugs: median (1st and 3rd quartiles) & $2(2.0,3.0)$ & $2(2.0,2.0)$ \\
$(S)$-KET with propofol: yes/no & $8 / 15$ & $9 / 10$ \\
Latency from SE to $(S)$-KET (days): median (1st and 3rd quartiles) & $3(2.0,5.5)$ & $3(2.0,7.0)$ \\
Duration of $(S)$-KET administration (days): median (1st and 3rd quartiles) & $4(2.0,7.5)$ & $4(2.5,6.0)$
\end{tabular}

$A E D$ antiepileptic drug, $F$ female, $M$ male, NICU neurological intensive care unit, $S E$ status epilepticus, $(S)$-KET $(S)$-ketamine

${ }^{a}$ Alive means that death did not occur within 4 weeks after SE

Table 4 Associations with the number of deaths

\begin{tabular}{|c|c|c|c|}
\hline Variable & Test & $p$ value (adjusted) ${ }^{\mathrm{a}}$ & Effect measure: estimate $(95 \% \mathrm{CI})$ \\
\hline Hypoxia: yes/no & E. Pearson's Chi-squared test & 1.00 & Odds ratio $^{\text {b }}: 0.56(0.15-2.08)$ \\
\hline Responder: yes/no & E. Pearson's Chi-squared test & 1.00 & Odds ratio: $2.15(0.58-8.00)$ \\
\hline Median infusion rate $\geq 2 \mathrm{mg} / \mathrm{kg} / \mathrm{h}$ : yes $/$ no & E. Pearson's Chi-squared test & 1.00 & Odds ratio: $0.73(0.21-2.56)$ \\
\hline Loading dose administered: yes/no & E. Pearson's Chi-squared test & 1.00 & Odds ratio: $0.16(0.02-1.45)$ \\
\hline Number of previously failed AEDs & Brunner-Munzel test & 1.00 & Relative effect ${ }^{\mathrm{c}}: 0.44(0.26-0.61)$ \\
\hline Duration of $(S)$-KET administration & Brunner-Munzel test & 1.00 & Relative effect: $0.49(0.31-0.68)$ \\
\hline Latency from SE to $(S)$-KET & Brunner-Munzel test & 1.00 & Relative effect: $0.54(0.36-0.72)$ \\
\hline Age & Brunner-Munzel test & 0.0014 & Relative effect: $0.80(0.66-0.94)$ \\
\hline
\end{tabular}

$A E D$ antiepileptic drug, $C I$ confidence interval, $S E$ status epilepticus, $(S)$-KET $(S)$-ketamine

a The reported $p$ values have been adjusted for multiple comparisons using the Bonferroni-Holm correction

b The reported odds ratio represents the quotient of the odds for dying given hypoxia $=$ yes and the odds for dying given hypoxia $=$ no. Analogous interpretations hold for the other odds ratios reported in the table

c This quantity can be interpreted as an estimate of the probability that the value of the variable is lower for the alive than for the deceased

sequential order of AEDs and not the exact timing could be assessed. All patients had several AEDs, and the effect of $(S)$-KET is hard to distinguish from the cumulative effect of the antiepileptic cocktails including propofol. In addition, the diagnosis of NCSE in comatose patients is impossible without an EEG [18]. Rate of misdiagnosis of NCSE could be minimized by using the electro-clinical diagnostic criteria for NCSE. But still there are borderline
EEG patterns, and sometimes there might have been an overlap between NCSE and severe encephalopathies, which might confound treatment response and outcome [20].

As we have quite small sample sizes, caution was needed when conducting the statistical analyses. We did not use the logistic regression model because small sample sizes may influence the validity of the statistical tests 
derived from the model [21]. Instead, we decided to use methods that are reliable even for small sample sizes. Moreover, the Brunner-Munzel test gives valid results also for non-normal, skewed data. However, an analysis accounting for the influence of several variables simultaneously was not possible because of the small sample sizes.

Adverse effects attributed to $(S)$-KET were not assessed. Because of the study's retrospective nature, there was no systematic evaluation of adverse effects. Therefore, under-ascertainment of adverse effects is a weakness of this study, which can only be overcome in a prospective study. This is the largest single center study with $(S)$-KET and the first report using exclusively the $S$ enantiomer of KET.

\section{Conclusion}

Intravenous $(S)$-KET had a good safety profile when used as a treatment for RSE and SRSE, but we did not find a higher efficacy than that with the racemic mixture. We did not find adverse events; they might be under-ascertained because of the small number of patients. Earlier treatment of SE with $(S)$-KET or the racemic mixture should be considered.

Acknowledgments Open access funding provided by Paracelsus Medical University.

\section{Compliance with Ethical Standards}

Funding There was no funding for the study and its publication.

Conflict of interest J Höfler received speaker's honoraria from UCB, and travel grants from UCB, Eisai, and Gerot Lanach. A. Rohracher received travel support from Eisai. G. Kalss received a travel grant from UCB Pharma and Eisai. J. Dobesberger received speaker honoraria from Gerot Lanach and travel support from Eisai, GlaxoSmithKline and Neurodata GmbH/Micromed Austria. M. Leitinger received a travel grant from Medtronics and UCB Pharma and speaker honorarium from Everpharma. G. Kuchukhidze received travel support from Eisai. H. Novak received speaker's honoraria from Astellas and CSC Angelini. E. Trinka has acted as a paid consultant to UCB, Biogen, Gerot Lanach, Newbridge, Sunovion, Bial, Cyberonics, Desitin Pharma, Eisai, Gerot, Böhringer, Sanofi, Medis and UCB. He has received research funding from UCB, Biogen-Idec, Red Bull, Merck, European Union, FWF (Österreichischer Fond zur Wissenschaftsförderung Bundesministerium für Wissenschaft und Forschung), Sanofi-Aventis, and speakers' honoraria from UCB, Biogen, Gerot Lanach, Bial, EISAI, Takeda, Newbridge, Sunovion, Novartis. A. Taylor, G. Zimmermann, K. Butz, G. Pilz have no conflicts of interest.

Ethical approval For this type of study, formal consent was not required.

Open Access This article is distributed under the terms of the Creative Commons Attribution-NonCommercial 4.0 International License (http://creativecommons.org/licenses/by-nc/4.0/), which permits any noncommercial use, distribution, and reproduction in any medium, provided you give appropriate credit to the original author(s) and the source, provide a link to the Creative Commons license, and indicate if changes were made.

\section{References}

1. Shorvon S, Ferlisi M. The outcome of therapies in refractory and super-refractory convulsive status epilepticus and recommendations for therapy. Brain. 2012;135(Pt 8):2314-28.

2. Mayer SA, Claassen J, Lokin J, Mendelsohn F, Dennis LJ, Fitzsimmons BF. Refractory status epilepticus: frequency, risk factors, and impact on outcome. Arch Neurol. 2002;59:2015-210.

3. Kellinghaus C, Stögbauer F. Treatment of status epilepticus in a large community hospital. Epilepsy Behav. 2012;23:235-40.

4. Lowenstein DH, Bleck T, Macdonald RL. It's time to revise the definition of Status epilepticus. Epilepsia. 1999;40(1):120-2.

5. Feng HJ, Mathews GC, Kao C, Macdonald RL. Alterations of GABA A-receptor function and allosteric modulation during development of status epilepticus. J Neurophysiol. 2008;99:1285-93.

6. Chen JW, Wasterlain CG. Status epilepticus: pathophysiology and management in adults. Lancet Neurol. 2006;5:246-56.

7. Jones S, Pahl C, Trinka E, Nashef L. A protocol for the inhospital emergency drug management of convulsive status epilepticus in adults. Pract Neurol. 2014;14:194-7.

8. Trinka E, Höfler J, Leitinger M, Brigo F. Pharmacotherapy for status epilepticus. Drugs. 2015;75:1499-521.

9. Borris DJ, Bertram EH, Kapur J. Ketamine controls prolonged status epilepticus. Epilepsy Res. 2000;42:117-22.

10. Mazarati AM, Wasterlain CG. $N$-methyl-D-asparate receptor antagonists abolish the maintenance phase of self-sustaining status epilepticus in rat. Neurosci Lett. 1999;23:187-90.

11. Oye I, Paulsen O, Maurset A. Effects of ketamine on sensory perception: evidence for a role of $N$-methyl-D-aspartate receptors. J Pharmacol Exp Ther. 1992;260(3):1209-13.

12. White PF, Schüttler J, Shafer A, Stanski DR, Horai Y, Trevor AJ. Comparative pharmacology of the ketamine isomers. Studies in volunteers. Br J Anaesth. 1985;57:197-203.

13. Engelhardt W, Stahl K, Marouche A, Hartung E. Recovery time after (S)-ketamine or ketamine racemate. Recovery time after short anesthesia in volunteers. Anaesthesist. 1998;47:184-92.

14. Beniczky S, Hirsch LJ, Kaplan PW, Pressler R, Bauer G, Aurlien $\mathrm{H}$, Brøgger JC, Trinka E. Unified EEG terminology and criteria for nonconvulsive status epilepticus. Epilepsia. 2013;54(Suppl 6):28-9.

15. Trinka E, Leitinger M. Which EEG patterns in coma are nonconvulsive status epilepticus? Epilepsy Behav. 2015;49:203-22.

16. Trinka E, Cock H, Hesdorffer D, Rossetti AO, Scheffer IE, Shinnar S, Shorvon S, Lowenstein DH. A definition and classification of status epilepticus-report of the ILAE Task Force on Classification of Status Epilepticus. Epilepsia. 2015;56(10):1515-23.

17. Shorvon S, Baulac M, Cross H, Trinka E, Walker M. TaskForce on Status Epilepticus of the ILAE Commission for European Affairs. The drug treatment of status epilepticus in Europe: consensus document from a workshop at the first London Colloquium on Status Epilepticus. Epilepsia. 2008;49(7):1277-85.

18. Bauer G, Trinka E. Nonconvulsive status epilepticus and coma. Epilepsia. 2010;51(2):177-90.

19. Trinka E, Höfler J, Leitinger M, Rohracher A, Kalss G, Brigo F. Pharmacologic treatment of status epilepticus. Expert Opin Pharmacother. 2016;17(4):513-34. 
20. Leitinger M, Kalss G, Rohracher A, Pilz G, Novak H, Höfler J, Deak I, Kuchukhidze G, Dobesberger J, Wakonig A, Trinka E. Predicting outcome of status epilepticus. Epilepsy Behav. 2015;49:126-30.

21. Peduzzi P, Concato J, Kemper E, Holford TR, Feinstein AR. A simulation study of the number of events per variable in logistic regression analysis. J Clin Epidemiol. 1996;49:1373-9.

22. Pearson ES. The choice of statistical tests illustrated on the interpretation of data classed in a $2 \times 2$ table. Biometrika. 1947;34:139-67.

23. Brunner E, Munzel U. The nonparametric Behrens-Fisher problem: asymptotic theory and a small-sample approximation. Biom J. 2000;42:17-25.

24. Holm S. A simple sequentially rejective multiple test procedure. Scand J Stat. 1979;6:65-70.

25. Agresti A. On logit confidence intervals for the odds ratio with small samples. Biometrics. 1999;55:597-602.

26. $\mathrm{R}$ Core Team. R A language and environment for statistical computing. R Foundation for Statistical Computing, Vienna, Austria, 2014. http://www.R-project.org/.

27. Wu YW, Shek DW, Garcia PA, Zhao S, Johnston SC. Incidence and mortality of generalized convulsive status epilepticus in California. Neurology. 2002;58:1070-6.

28. Kowalski RG, Ziai WC, Rees RN, Werner JK Jr, Kim G, Goodwin H, Geocadin RG. Third-line antiepileptic therapy and outcome in status epilepticus: the impact of vasopressor use and prolonged mechanical ventilation. Crit Care Med. 2012;40(9):2677-84.

29. Sutter R, Marsch S, Fuhr P, Kaplan PW, Rüegg S. Anesthetic drugs in status epilepticus: risk or rescue? A 6-year cohort study. Neurology. 2014;82:656-64.

30. Marchi NA, Novy J, Faouzi M, Stähli C, Burnand B, Rossetti AO. Status epilepticus: impact of therapeutic coma on outcome. Crit Care Med. 2015;43(5):1003-9.

31. Gaspard N, Foreman B, Judd LM, Brenton JN, Nathan BR, McCoy BM, Al-Otaibi A, Kilbride R, Fernández IS, Mendoza L, Samuel S, Zakaria A, Kalamangalam GP, Legros B, Szaflarski JP, Loddenkemper T, Hahn CD, Goodkin HP, Claassen J, Hirsch LJ, Laroche SM. Intravenous ketamine for the treatment of refractory status epilepticus: a retrospective multicenter study. Epilepsia. 2013;54(8):1498-503.

32. Sabharwal V, Ramsay E, Martinez R, Shumate R, Khan F, Dave $\mathrm{H}$, Iwuchukwu I, McGrade H. Propofol-ketamine combination therapy for effective control of super-refractory status epilepticus. Epilepsy Behav. 2015;52:264-6.

33. Synowiec AS, Singh DS, Yenugadhati V, Valeriano JP, Schramke CJ, Kelly KM. Ketamine use in the treatment of refractory status epilepticus. Epilepsy Res. 2013;105:183-8.

34. Basha MM, Alqallaf A, Shah AK. Drug-induced EEG pattern predicts effectiveness of ketamine in treating refractory status epilepticus. Epilepsia. 2015;56(4):44-8.

35. Koubeissi M, Alshekhlee A. In-hospital mortality of generalized convulsive status epilepticus: a large US sample. Neurology. 2007;69:886-93.

36. Walker MC, Howard RS, Smith SJ, Miller DH, Shorvon SD, Hirsch NP. Diagnosis and treatment of status epilepticus on a neurological intensive care unit. QJM. 1996;89:913-20.

37. Ubogu EE, Sagar SM, Lerner AJ, Maddux BN, Suarez JI, Werz MA. Ketamine for refractory status epilepticus: a case of possible ketamine-induced neurotoxicity. Epilepsy Behav. 2003;4:70-5.

38. Kofke WA, Bloom MJ, Van Cott A, Brenner RP. Electrographic tachyphylaxis to etomidate and ketamine used for refractory status epilepticus controlled with isoflurane. J Neurosurg Anesthesiol. 1997;9:269-72.

39. Robakis TK, Hirsch LJ. Literature review, case report, and expert discussion of prolonged refractory status epilepticus. Neurocrit Care. 2006;4:35-46.

40. Prüss H, Holtkamp M. Ketamine successfully terminates malignant status epilepticus. Epilepsy Res. 2008;82:219-22.

41. Hsieh CY, Sung PS, Tsai JJ, Huang CW. Terminating prolonged refractory status epilepticus using ketamine. Clin Neuropharmacol. 2010;33:165-7.

42. Yeh PS, Shen HN, Chen TY. Oral ketamine controlled refractory nonconvulsive status epilepticus in an elderly patient. Seizure. 2011;20:723-6.

43. Kramer AH. Early ketamine to treat refractory status epilepticus. Neurocrit Care. 2012;16:299-305.

44. Zeiler FA, Kaufmann AM, Gillman LM, West M, Silvaggio J. Ketamine for medically refractory status epilepticus after elective aneurysm clipping. Neurocrit Care. 2013;19:119-24.

45. Shrestha GS, Joshi P, Chhetri S, Karn R, Acharya SP. Intravenous ketamine for treatment of super-refractory convulsive status epilepticus with septic shock: a report of two cases. Indian J Crit Care Med. 2015;19:283-5. 